\title{
Sexual determination of long bones in recent Japanese
}

\author{
KAZUHIRO SAKAUE ${ }^{1 *}$ \\ Department of Anatomy and Anthropology, Tohoku University School of Medicine, \\ Seiryo-machi, Aoba-ku, Sendai, Miyagi, 980-8575 Japan ${ }^{1}$
}

Received 9 January 2003; accepted 2 October 2003

\begin{abstract}
Sexual diagnosis of skeletons is of importance to physical and forensic anthropologists. The present study attempts to provide a basis from which one might choose a variable of a long bone that is most suitable in sexual assessments of skeletal material. A total of 47 variables of the humerus, radius, ulna, femur, and tibia of 64 recent-modern Japanese (32 male, 32 female) were investigated. The data were analyzed using the t-test and the stepwise discriminant analysis. The width of the articular surface of the distal humerus, the sagittal head diameter of the radius, the diaphyseal cross-section area or the articular breadth of the ulna, the bicondylar width or the transverse diameter of the lateral condyle of the femur, and the proximal epiphyseal breadth of the tibia were useful in sexual diagnosis of each of the long bones. Total accuracies of sex determination using these variables ranged from 91 to $95 \%$. Among these measurements, sexual dimorphism tended to be greatest in the breadth diameters of the elbow and knee joints.
\end{abstract}

Key words: discriminant analysis, sex identification, epiphyseal diameters, recent Japanese

\section{Introduction}

Sex determination of the human skeleton has been studied in forensic and physical anthropology (Krogman, 1962). There are many studies on the metric diagnosis of sex in bones. Long bones have especially been used because of the ease of defining measurements, better preservation, and so on. Former studies have shown that some combination of diameters of the long bones have as strong a discriminatory power as do the pelvis or cranium (Pons, 1955; Hanihara, 1958).

In past studies, sex determination of individual or limited sets of long bones has been attempted. It has been pointed out that a certain set of variables tends to be better for sex diagnosis than others. There are some studies of sexual diagnosis using only the humerus (Iscan et al., 1998), the ulna (Purkait, 2001) and arm bones (Liu, 1989; Holman and Bennett, 1991; Mall et al., 2001). After Pons (1955), the femur is the most studied of all bones in the determination of sex (Van Gerven, 1972; Black, 1978; Dibennardo and Taylor, 1983; Asala, 2001), while there are some studies using only the tibia (Iscan and Miller-Shaivitz, 1984; Holland, 1991; Iscan et al., 1994). Liu et al. (1989) investigated three lower limb bones, the femur, tibia, and fibula. Dittrick and Suchey (1986) studied nine variables of the femur and nine variables of the humerus. Some studies considered all the long bones in their assessments of sex (Hanihara, 1958; Nakahashi and Nagai, 1986; Tagaya, 1987; Safont et al., 2000). In these studies, availability, group differences and the application of

\footnotetext{
* Corresponding author. e-mail: k-sakaue@mail.cc.tohoku.ac.jp phone: +81-22-717-8027; fax: +81-22-717-8030

Published online 16 April 2004

in J-STAGE (www.jstage.jst.go.jp) DOI: 10.1537/ase.00067
}

discriminant functions were discussed.

In these past studies, it has been pointed out that epiphyseal or diaphyseal diameters of the long bones tend to have more power for sexual diagnosis than other variables like bone lengths. However there are limited discussions about which variable of which long bone may be the best discriminator of sex. Safont et al. (2000) showed that, among eight long bone shaft circumferences, tibial circumference at the nutrient foramen was the best variable in their discriminant analysis. Mall et al. (2001) demonstrated that, among nine variables of the long bones of the arm, humeral head diameter allowed the best distinction of sex. From a forward stepwise discriminant analysis of long bones of the arm, Liu (1989) considered that the sagittal head diameter of the radius was the best. Liu et al. (1989) concluded that upper epiphyseal length of the femur was the best among 37 variables of the long bones of the leg.

Thus, there are no fixed criteria regarding which variable(s) of which bone should be chosen in order to assess its sex. The purpose of this study is to investigate which variable of which long bone is the best in the metric diagnosis of sex.

\section{Materials and Methods}

The recent to modern Japanese skeletal materials used in this study belong to The University Museum, The University of Tokyo, and the Department of Anatomy, Chiba University School of Medicine. The sex and age of all individuals are known. In order to simplify the comparison between sexes, the sample size of each sex was made the same at 32 individuals. The sample was selected to range in age from closure of all epiphyses to 50 years. Only individuals with no bone fractures, no osteoarthritis, no periostitis, 
Table 1. The definition of variables for each bone

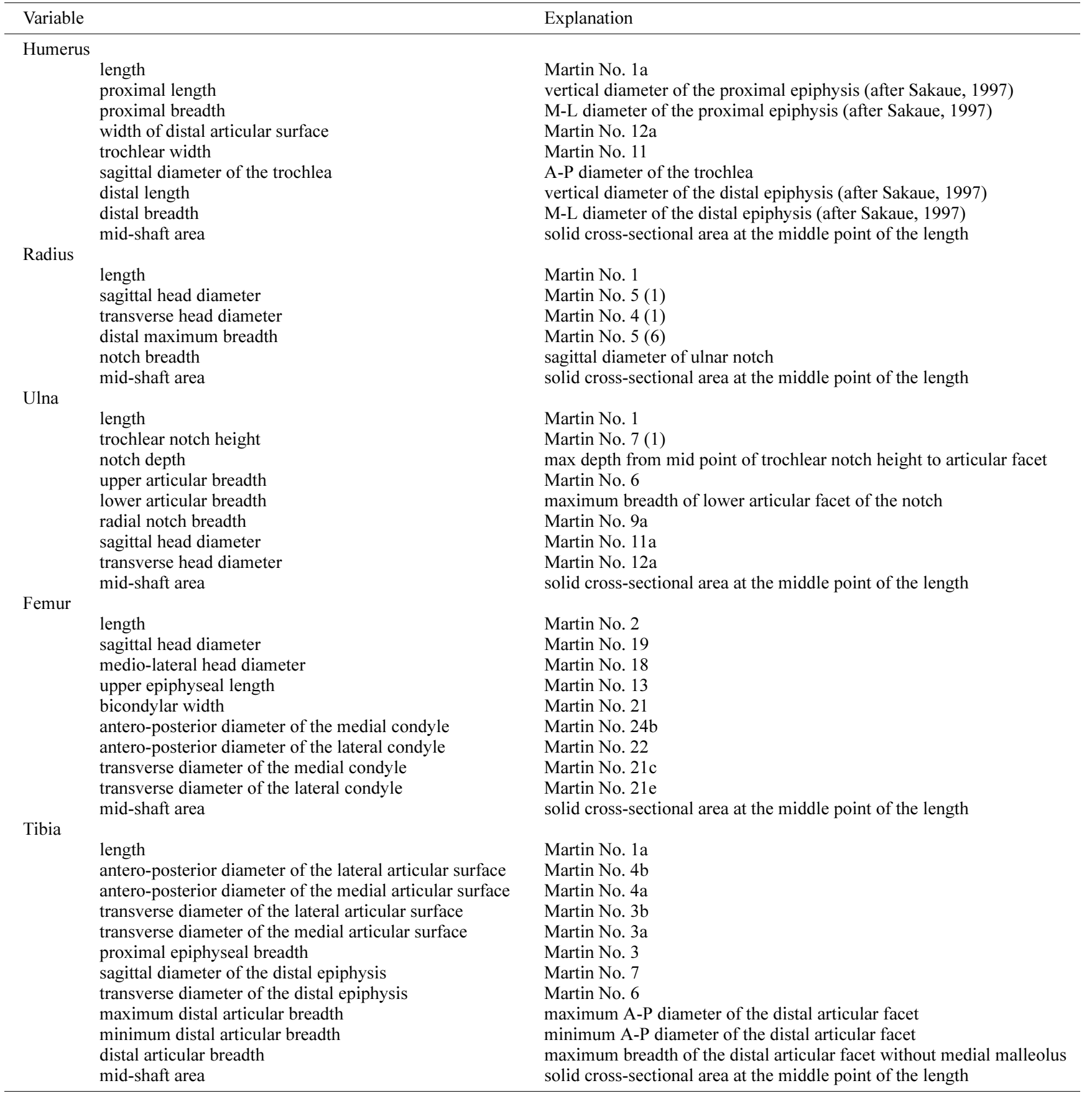

See Baba (1991) for exact methods taken for Martin's measurements.

and no other apparent pathological changes were selected. A total of 46 measurements were examined (Table 1), and all measurements were taken on the right side. Mid-shaft areas were measured with Scion Image Beta 4.02, using sectioned molds of silicon putty. In selecting variables, one criterion considered was to diminish intra-observer error. For this purpose, for each variable 10 repeated measures were taken in a randomly chosen sample of 10 individuals, and the standard deviations of these were shown to be less than 0.1. Although shaft circumferences have often been included in previous discriminant analyses, these were not considered in the present study because of poorer metrical repeatability.

Statistical analyses were undertaken as follows. First, the one-sample Kolmogorov-Smirnov test was conducted for all variables in each sex in order to test for any deviations from a normal distribution. Second, the t-values of the two-sample t-test were calculated in order to compare the relative significance of sexual difference between variables. The tvalue can be seen as a quantitative distance between sexes if the sample sizes are the same. Prior to the discriminant anal- 
ysis, the Box's M test was done for each long bone to test for equivalence of the covariance matrix. Third, discriminant analysis with one variable, and a forward stepwise discriminant analysis with all variables were conducted for each long bone. In the discriminant analysis with one variable, the Wilks' lambda and the correctly classified percentages were calculated. The Wilks' lambda is the ratio of the withingroup and total sum of squares. Values close to zero imply high predictability of membership. All statistical analyses except the Box's M test were done with SYSTAT 10.0. The Box's M test was done with S.P.S.S. 11.0. A statistically significant level of $5 \%$ is referred to in the following descriptions of the present study.

\section{Results}

The distribution of all variables of each sex did not differ from normal at the statistically significant level. All variables showed statistically significant sexual differences in the two-sample t-tests. Results of the upper limb long bones are shown in Table 2. In the humerus, the t-values of the width of the distal articular surface and the distal breadth were higher than those of the other variables. The Wilks' lambda values were low, and the correctly classified percentages reached $94 \%$ in these variables. The t-value of humeral length was relatively low, and the correct percentage of clas- sification of humeral length was one of the lowest of all the variables. In the radius, the t-value of the sagittal head diameter was the highest, and that of the transverse head diameter was second. The t-value of radial length was not as low as that of humeral length. The Wilks' lambdas of all radial variables except length and notch breadth did not exceed 0.4 . The correctly classified percentages were higher than $80 \%$ in all variables of the radius. In the ulna, the t-value of midshaft area was the highest and its Wilks' lambda was the smallest. The t-values of the proximal articular breadths were also high. As in the radius, the t-value of ulnar length was not so low. All of the Wilks' lambda values exceeded 0.4 except for those of the lower articular breadth and midshaft area of the ulna, although the correctly classified percentages were not so low.

Results of the lower limb long bones are shown in Table 3. In the femur, the t-value of bicondylar width was the highest. The t-value of femoral length was the lowest of all the femoral variables. The Wilks' lambda values of bicondylar width and transverse diameter of the lateral condyle were the lowest, although their correctly classified percentages were not so high. The correctly classified percentages of all the femoral variables tended to be relatively low. In the tibia, the t-value and the correctly classified percentage of the proximal epiphyseal breadth were especially high, and its Wilks' lambda was very low. The t-value of tibial length was rela-

Table 2. Basic statistics and discriminant analysis of each variable in upper limb bones

\begin{tabular}{|c|c|c|c|c|c|c|c|c|c|}
\hline \multirow[b]{2}{*}{ Humerus } & \multicolumn{2}{|c|}{ Mean } & \multicolumn{2}{|c|}{ S.D. } & \multirow[b]{2}{*}{ t-value } & \multicolumn{2}{|c|}{ Discriminant functions } & \multirow[b]{2}{*}{ Wilks' $\lambda$} & \multirow{2}{*}{$\begin{array}{c}\text { Correctly } \\
\text { classified (\%) }\end{array}$} \\
\hline & male & female & male & female & & $\begin{array}{c}\text { Raw } \\
\text { coefficient }\end{array}$ & Constant & & \\
\hline length & 294.45 & 273.73 & 14.27 & 13.75 & 5.92 & 0.071 & -20.273 & 0.639 & 70.0 \\
\hline proximal length & 33.68 & 31.54 & 2.83 & 1.74 & 3.65 & 0.425 & -13.867 & 0.823 & 70.0 \\
\hline proximal breadth & 48.39 & 42.86 & 2.62 & 1.97 & 9.56 & 0.432 & -19.700 & 0.404 & 88.0 \\
\hline width of distal articular surface & 44.92 & 38.01 & 1.96 & 1.93 & 14.20 & 0.514 & -21.320 & 0.235 & 95.0 \\
\hline trochlear width & 26.44 & 22.90 & 1.72 & 1.49 & 8.81 & 0.621 & -15.329 & 0.443 & 70.0 \\
\hline distal length & 24.88 & 22.65 & 2.61 & 1.70 & 4.07 & 0.454 & -10.800 & 0.789 & 77.0 \\
\hline distal breadth & 59.18 & 51.11 & 2.80 & 2.49 & 12.20 & 0.378 & -20.817 & 0.294 & 94.0 \\
\hline sagital diameter of the trochlea & 25.98 & 21.96 & 1.70 & 1.28 & 10.71 & 0.665 & -15.942 & 0.351 & 89.0 \\
\hline mid-shaft area & 311.68 & 225.36 & 43.13 & 38.08 & 8.49 & 0.025 & -6.600 & 0.457 & 88.0 \\
\hline \multirow[b]{2}{*}{ Radius } & \multicolumn{2}{|c|}{ Mean } & \multicolumn{2}{|c|}{ S.D. } & \multirow{2}{*}{ t-value } & \multicolumn{2}{|c|}{ Discriminant functions } & \multirow[b]{2}{*}{ Wilks' $\lambda$} & \multirow{2}{*}{$\begin{array}{c}\text { Correctly } \\
\text { classified (\%) }\end{array}$} \\
\hline & male & female & male & female & & $\begin{array}{c}\text { Raw } \\
\text { coefficient }\end{array}$ & Constant & & \\
\hline length & 221.29 & 200.28 & 11.03 & 9.54 & 8.15 & 0.097 & -20.440 & 0.482 & 80.0 \\
\hline sagital head diameter & 22.58 & 19.19 & 1.28 & 1.06 & 11.52 & 0.850 & -17.753 & 0.318 & 92.0 \\
\hline transverse head diameter & 21.39 & 18.47 & 1.36 & 0.82 & 10.37 & 0.888 & -17.688 & 0.365 & 91.0 \\
\hline distal maximum breadth & 27.97 & 24.65 & 1.40 & 1.16 & 10.33 & 0.778 & -20.477 & 0.367 & 92.0 \\
\hline notch breadth & 16.71 & 15.02 & 1.27 & 0.93 & 6.09 & 0.900 & -14.283 & 0.625 & 88.0 \\
\hline mid-shaft area & 116.40 & 84.27 & 14.19 & 12.30 & 9.67 & 0.075 & -7.557 & 0.396 & 91.0 \\
\hline \multirow[b]{2}{*}{ Ulna } & \multicolumn{2}{|c|}{ Mean } & \multicolumn{2}{|c|}{ S.D. } & \multirow[b]{2}{*}{ t-value } & \multicolumn{2}{|c|}{ Discriminant functions } & \multirow[b]{2}{*}{ Wilks' $\lambda$} & \multirow{2}{*}{$\begin{array}{c}\text { Correctly } \\
\text { classified (\%) }\end{array}$} \\
\hline & male & female & male & female & & $\begin{array}{c}\text { Raw } \\
\text { coefficient }\end{array}$ & Constant & & \\
\hline length & 240.40 & 218.18 & 11.14 & 10.06 & 8.38 & 0.094 & -21.608 & 0.469 & 83.0 \\
\hline trochlear notch height & 22.97 & 19.72 & 1.98 & 1.75 & 6.96 & 0.535 & -11.413 & 0.561 & 80.0 \\
\hline notch depth & 12.08 & 10.41 & 1.15 & 1.15 & 5.85 & 0.873 & -9.814 & 0.644 & 80.0 \\
\hline upper articular breadth & 25.28 & 21.25 & 1.76 & 1.74 & 9.23 & 0.573 & -13.326 & 0.421 & 84.0 \\
\hline lower articular breadth & 25.36 & 20.96 & 2.05 & 1.51 & 9.78 & 0.555 & -12.862 & 0.393 & 91.0 \\
\hline radial notch breadth & 19.23 & 16.25 & 3.66 & 2.97 & 3.58 & 0.300 & -5.323 & 0.829 & 72.0 \\
\hline sagital head diameter & 20.67 & 18.17 & 1.12 & 1.12 & 8.91 & 0.892 & -17.316 & 0.438 & 88.0 \\
\hline transverse head diameter & 17.67 & 15.09 & 1.43 & 1.26 & 7.68 & 0.744 & -12.193 & 0.516 & 83.0 \\
\hline mid-shaft area & 129.19 & 90.47 & 15.29 & 14.75 & 10.31 & 0.067 & -7.313 & 0.385 & 92.0 \\
\hline
\end{tabular}


Table 3. Basic statistics and discriminant analysis of each variable in lower limb bones

\begin{tabular}{|c|c|c|c|c|c|c|c|c|c|}
\hline \multirow[b]{2}{*}{ Femur } & \multicolumn{2}{|c|}{ Mean } & \multicolumn{2}{|c|}{ S.D. } & \multirow{2}{*}{ t-value } & \multicolumn{2}{|c|}{ Discriminant functions } & \multirow{2}{*}{ Wilks' $\lambda$} & \multirow{2}{*}{$\begin{array}{c}\text { Correctly } \\
\text { classified (\%) }\end{array}$} \\
\hline & male & female & male & female & & $\begin{array}{c}\text { Raw } \\
\text { coefficient }\end{array}$ & Constant & & \\
\hline length & 404.26 & 375.00 & 20.47 & 20.64 & 5.69 & 0.049 & -18.961 & 0.656 & 75.0 \\
\hline sagittal head diameter & 45.25 & 40.21 & 2.19 & 2.00 & 9.63 & 0.477 & -20.397 & 0.401 & 91.0 \\
\hline medio-lateral head diameter & 45.61 & 40.49 & 2.24 & 1.95 & 9.75 & 0.479 & -20.636 & 0.393 & 88.0 \\
\hline upper epiphyseal length & 87.49 & 79.15 & 4.81 & 3.83 & 7.67 & 0.229 & -19.116 & 0.513 & 81.0 \\
\hline bicondylar width & 79.13 & 69.74 & 3.93 & 3.21 & 10.46 & 0.278 & -20.699 & 0.361 & 91.0 \\
\hline $\begin{array}{l}\text { antero-posterior diameter of } \\
\text { the medial condyle }\end{array}$ & 57.70 & 52.02 & 2.94 & 2.36 & 8.52 & 0.375 & -20.598 & 0.461 & 81.0 \\
\hline $\begin{array}{l}\text { antero-posterior diameter of } \\
\text { the lateral condyle }\end{array}$ & 60.53 & 54.35 & 2.45 & 2.75 & 9.50 & 0.384 & -22.038 & 0.407 & 91.0 \\
\hline $\begin{array}{l}\text { transverse diameter of the } \\
\text { medial condyle }\end{array}$ & 25.07 & 22.91 & 1.82 & 1.58 & 5.08 & 0.587 & -14.086 & 0.705 & 70.0 \\
\hline $\begin{array}{l}\text { transverse diameter of the } \\
\text { lateral condyle }\end{array}$ & 28.52 & 24.32 & 1.82 & 1.47 & 10.17 & 0.606 & -16.001 & 0.375 & 88.0 \\
\hline mid-shaft area & 504.29 & 397.71 & 59.58 & 45.58 & 8.04 & 0.019 & -8.503 & 0.480 & 86.0 \\
\hline \multirow[b]{2}{*}{ Tibia } & \multicolumn{2}{|c|}{ Mean } & \multicolumn{2}{|c|}{ S.D. } & & \multicolumn{2}{|c|}{ Discriminant functions } & \multirow[b]{2}{*}{ Wilks' $\lambda$} & \multirow{2}{*}{$\begin{array}{c}\text { Correctly } \\
\text { classified (\%) }\end{array}$} \\
\hline & male & female & male & female & t-value & $\begin{array}{c}\text { Raw } \\
\text { coefficient }\end{array}$ & Constant & & \\
\hline length & 329.05 & 308.18 & 17.67 & 16.25 & 4.92 & 0.059 & -18.770 & 0.719 & 72.0 \\
\hline $\begin{array}{l}\text { antero-posterior diameter of } \\
\text { the lateral articular surface }\end{array}$ & 39.86 & 35.44 & 2.15 & 2.35 & 7.86 & 0.445 & -16.746 & 0.502 & 89.0 \\
\hline $\begin{array}{l}\text { antero-posterior diameter of } \\
\text { the medial articular surface }\end{array}$ & 46.56 & 41.35 & 3.15 & 2.33 & 7.53 & 0.361 & -15.877 & 0.523 & 84.0 \\
\hline $\begin{array}{l}\text { transverse diameter of the } \\
\text { lateral articular surface }\end{array}$ & 31.35 & 26.52 & 1.85 & 1.97 & 10.12 & 0.523 & -15.145 & 0.377 & 92.0 \\
\hline $\begin{array}{l}\text { transverse diameter of the } \\
\text { medial articular surface }\end{array}$ & 31.43 & 28.28 & 1.29 & 1.62 & 8.63 & 0.683 & -20.402 & 0.455 & 86.0 \\
\hline proximal epiphyseal breadth & 74.45 & 65.80 & 3.15 & 2.77 & 11.68 & 0.328 & -22.989 & 0.333 & 94.0 \\
\hline $\begin{array}{l}\text { sagittal diameter of the distal } \\
\text { epiphysis }\end{array}$ & 37.38 & 33.38 & 2.15 & 1.82 & 8.05 & 0.502 & -17.760 & 0.489 & 86.0 \\
\hline $\begin{array}{l}\text { transverse diameter of the } \\
\text { distal epiphysis }\end{array}$ & 47.93 & 42.41 & 2.50 & 1.92 & 9.91 & 0.448 & -20.235 & 0.388 & 89.0 \\
\hline $\begin{array}{l}\text { maximum distal articular } \\
\text { breadth }\end{array}$ & 31.63 & 28.56 & 2.01 & 1.44 & 7.02 & 0.572 & -17.202 & 0.557 & 83.0 \\
\hline $\begin{array}{l}\text { minimum distal articular } \\
\text { breadth }\end{array}$ & 25.16 & 23.96 & 2.31 & 1.59 & 2.42 & 0.505 & -12.407 & 0.914 & 59.0 \\
\hline distal articular breadth & 34.38 & 32.66 & 2.22 & 2.70 & 2.79 & 0.405 & -13.567 & 0.889 & 61.0 \\
\hline mid-shaft area & 418.79 & 318.55 & 50.30 & 39.98 & 8.82 & 0.022 & -8.113 & 0.440 & 91.0 \\
\hline
\end{tabular}

tively low.

Among all the variables, the best discriminators (high tvalues, low Wilks' lambda, and high percentages of correct classification) were the width of the distal articular surface and the distal epiphyseal breadth of the humerus. Proximal epiphyseal breadth of the tibia was the next best discriminator. In general, epiphyseal breadths showed higher t-values than lengths in all the long bones, but this was less clear in the forearm bones. The t-values of the mid-shaft areas were moderately high in all the long bones.

There were no statistically significant differences between sexes, as examined by the Box's M test, in the covariance matrices of each of the long bones. Thus, the linear discriminant analysis can be applied to this data set. Tables 4 and 5 summarize the results of the multivariate discriminant analyses. The variables are listed in ascending order as determined by the forward stepwise procedure with all variables of each bone.

In the humerus, the distal epiphyseal diameters were relatively important in the determination of sex. This could be seen clearly by the fact that the correctly classified percentages reached $97 \%$ and did not change after step 2 . Among the radial variables, the sagittal head diameter was the best.
It had a relatively strong discriminatory power so that the correctly classified percentage and Wilks' lambda did not change after step 2 . In the ulna, the mid-shaft area and the upper articular breadth were good in sexual diagnosis. The correctly classified percentages of step 4 reached $97 \%$. In addition to the ulna mid-shaft area and the upper articular breadth, the length of the ulna was important in the determination of sex.

In the femur, the transverse diameters of the distal epiphysis were good discriminators. The dimension of the lateral condyle was especially important in the determination of sex. However, the correctly classified percentages tended to be low and the Wilks' lambda was relatively high. Thus, in the present Japanese sample, the discriminatory power of the femur was inferior to that of the other long bones. In the tibia, the proximal epiphyseal breadth had the highest power in sexing. It was such an efficient discriminator that the correctly classified percentage reached $94 \%$, and the Wilks' lambda was relatively low at the first discriminant step.

Compared across bones, the width of the distal articular surface and distal breadth of the humerus, the sagittal head diameter of the radius, and the proximal epiphyseal breadth of the tibia were most prominent in discriminating sex. 
Table 4. Summary of stepwise procedure with all variables in each upper limb bone

\begin{tabular}{|c|c|c|c|}
\hline Step & Humerus & $\begin{array}{l}\text { Wilks's } \\
\text { lambda }\end{array}$ & $\begin{array}{c}\text { Correctly } \\
\text { classified (\%) }\end{array}$ \\
\hline 1 & $\begin{array}{l}\text { width of distal articular } \\
\text { surface }\end{array}$ & 0.235 & 95.0 \\
\hline 2 & distal breadth & 0.221 & 97.0 \\
\hline 3 & trochlear width & 0.215 & 97.0 \\
\hline 4 & mid-shaft area & 0.211 & 97.0 \\
\hline 5 & distal length & 0.209 & 97.0 \\
\hline 6 & proximal length & 0.207 & 97.0 \\
\hline 7 & $\begin{array}{l}\text { sagittal diameter of the } \\
\text { trochlea }\end{array}$ & 0.204 & 97.0 \\
\hline 8 & proximal breadth & 0.203 & 97.0 \\
\hline 9 & length & 0.203 & 97.0 \\
\hline Step & Radius & $\begin{array}{l}\text { Wilks's } \\
\text { lambda }\end{array}$ & $\begin{array}{c}\text { Correctly } \\
\text { classified (\%) }\end{array}$ \\
\hline 1 & sagittal head diameter & 0.318 & 92.0 \\
\hline 2 & mid-shaft area & 0.275 & 94.0 \\
\hline 3 & distal maximum breadth & 0.267 & 95.0 \\
\hline 4 & length & 0.261 & 94.0 \\
\hline 5 & notch breadth & 0.261 & 95.0 \\
\hline 6 & transverse head diameter & 0.261 & 95.0 \\
\hline Step & Ulna & $\begin{array}{l}\text { Wilks's } \\
\text { lambda }\end{array}$ & $\begin{array}{c}\text { Correctly } \\
\text { classified (\%) }\end{array}$ \\
\hline 1 & mid-shaft area & 0.368 & 92.0 \\
\hline 2 & upper articular breadth & 0.312 & 95.0 \\
\hline 3 & length & 0.292 & 95.0 \\
\hline 4 & trochlear notch height & 0.288 & 97.0 \\
\hline 5 & sagittal head diameter & 0.286 & 97.0 \\
\hline 6 & notch depth & 0.283 & 97.0 \\
\hline 7 & lower articular breadth & 0.282 & 97.0 \\
\hline 8 & transverse head diameter & 0.281 & 97.0 \\
\hline 9 & radial notch breadth & 0.281 & 97.0 \\
\hline
\end{tabular}

Among the remaining variables, the upper articular breadth of the ulna and the bicondylar breadth of the femur were also good discriminators, suggesting that the variables most suitable for sexual determination are concentrated in the breadths of the elbow and knee joints. Table 6 shows the result of discriminant analysis using the best variables of each bone. In this analysis, the width of the articular surface of the humerus and the proximal epiphyseal breadth of the tibia were selected in the forward stepwise analysis.

\section{Discussion}

The purpose of this study was to investigate which variable of which bone is the best for the metric diagnosis of sex in long bones. Judging from the t-values and the results of the stepwise discriminant analysis, the width of the distal articular surface of the humerus, the sagittal head diameter of the radius, the mid-shaft cross-sectional area or the lower articular breadth of the ulna, the bicondylar width of the femur, and the proximal epiphyseal breadth of the tibia can be considered to be the most useful for sexual diagnosis in each of the long bones. Especially the breadth diameters of the distal epiphysis of the humerus and the proximal epiphyseal of the tibia were powerful discriminators, judging from the Wilks' lambda values and the correctly classified percentages. The present study also showed that epiphyseal
Table 5. Summary of stepwise procedure with all variables in each lower limb bone

\begin{tabular}{|c|c|c|c|}
\hline Step & Femur & $\begin{array}{l}\text { Wilks's } \\
\text { lambda }\end{array}$ & $\begin{array}{c}\text { Correctly } \\
\text { classified (\%) }\end{array}$ \\
\hline 1 & bicondylar width & 0.362 & 91.0 \\
\hline 2 & $\begin{array}{l}\text { transverse diameter } \\
\text { of the lateral condyle }\end{array}$ & 0.324 & 94.0 \\
\hline 3 & $\begin{array}{l}\text { antero-posterior diameter } \\
\text { of the lateral condyle }\end{array}$ & 0.310 & 94.0 \\
\hline 4 & length & 0.298 & 95.0 \\
\hline 5 & mid-shaft area & 0.294 & 98.0 \\
\hline 6 & $\begin{array}{l}\text { antero-posterior diameter } \\
\text { of the medial condyle }\end{array}$ & 0.292 & 97.0 \\
\hline 7 & medio-lateral head diameter & 0.291 & 97.0 \\
\hline 8 & sagittal head diameter & 0.289 & 95.0 \\
\hline 9 & $\begin{array}{l}\text { transverse diameter of } \\
\text { the medial condyle }\end{array}$ & 0.289 & 95.0 \\
\hline 10 & upper epiphyseal length & 0.289 & 95.0 \\
\hline Step & Tibia & $\begin{array}{l}\text { Wilks's } \\
\text { lambda }\end{array}$ & $\begin{array}{c}\text { Correctly } \\
\text { classified (\%) }\end{array}$ \\
\hline 1 & proximal epiphyseal breadth & 0.313 & 94.0 \\
\hline 2 & mid-shaft area & 0.292 & 94.0 \\
\hline 3 & length & 0.280 & 95.0 \\
\hline 4 & $\begin{array}{l}\text { transverse diameter of the } \\
\text { lateral articular surface }\end{array}$ & 0.271 & 94.0 \\
\hline 5 & $\begin{array}{l}\text { antero-posterior diameter } \\
\text { of the medial articular surface }\end{array}$ & 0.265 & 94.0 \\
\hline 6 & $\begin{array}{l}\text { transverse diameter of } \\
\text { the distal epiphysis }\end{array}$ & 0.258 & 95.0 \\
\hline 7 & distal articular breadth & 0.248 & 97.0 \\
\hline 8 & $\begin{array}{l}\text { minimum distal articular } \\
\text { breadth }\end{array}$ & 0.242 & 97.0 \\
\hline 9 & $\begin{array}{l}\text { transverse diameter of the } \\
\text { medial articular surface }\end{array}$ & 0.238 & 95.0 \\
\hline 10 & $\begin{array}{l}\text { sagittal diameter of the } \\
\text { distal epiphysis }\end{array}$ & 0.235 & 97.0 \\
\hline 11 & $\begin{array}{l}\text { antero-posterior diameter } \\
\text { of the lateral articular surface }\end{array}$ & 0.234 & 95.0 \\
\hline 12 & $\begin{array}{l}\text { maximum distal articular } \\
\text { breadth }\end{array}$ & 0.234 & 95.0 \\
\hline
\end{tabular}

Table 6. Summary of stepwise procedure with the best variables in each long bone

\begin{tabular}{|c|c|c|c|c|}
\hline Step & Bone & Variable & $\begin{array}{l}\text { Wilks's } \\
\text { lambda }\end{array}$ & $\begin{array}{c}\text { Correctly } \\
\text { classified (\%) }\end{array}$ \\
\hline 1 & Humerus & $\begin{array}{l}\text { width of distal articular } \\
\text { surface }\end{array}$ & 0.235 & 95.0 \\
\hline 2 & Tibia & $\begin{array}{l}\text { proximal epiphyseal } \\
\text { breadth }\end{array}$ & 0.226 & 97.0 \\
\hline 3 & Ulna & mid-area & 0.220 & 98.0 \\
\hline 4 & Radius & sagittal head diameter & 0.218 & 98.0 \\
\hline 5 & Femur & bicondylar width & 0.215 & 98.0 \\
\hline
\end{tabular}

parts tend to be more useful for sex determination than the length of long bones. Since Dwight (1904/05) pointed this out almost a century ago, the importance of the diameters of the epiphyseal parts has been accounted for by previous studies (e.g. Dittrick and Suchey, 1986). In the present study, it was further found that sexual differences are especially strong in the breadth diameters of the elbow and knee joints.

There are many reports from past studies that support this conclusion. In the humerus, the distal breadth has been 
pointed out either directly or indirectly as good for sexing (Dwight, 1904/05; Dittrick and Suchey, 1986; Liu, 1989; Iscan et al., 1998; Mall et al., 2001). Liu (1989) and Mall et al. (2001) pointed out the discriminatory power of radial head diameters. Van Gerven (1972) studied 17 variables of the femur and found that epicondylar breadth was the most powerful in sexing. Liu et al. (1989), Holland (1991) and Iscan et al. (1994) concluded that the epiphyseal breadth of the tibia was better than the other variables of that bone in sexual diagnosis.

There are, however, some differences between the results of this study and those of some of previous studies. In particular, the head diameters of the humerus and femur have previously been reported as good indicators of sex (Dibennardo and Taylor, 1983; Dittrick and Suchey, 1986; Liu, 1989; Liu et al., 1989; Iscan et al., 1998; Mall et al., 2001). In the present study, these variables were not as good a discriminator as the breadths of the elbow or knee joints. In another study, Safont et al. (2000) showed that the circumference at the nutrient foramen of the tibia was the best variable in a discriminant function, and the tuberosity circumference of the radius was second. This difference of results cannot be easily interpreted, because the measurements of the bone shafts differ between that and the present studies.

Holland (1991), who investigated sex determination with the proximal tibia, noted that "because the ends of the tibia are subjected to heavy stress during an individual's life, and because the stress may have a sexual component, the ends should be useful in determining sex." But, in the present study, the diaphyseal cross-sectional areas that should also reflect mechanical stress were not as good a discriminator as the epiphyseal parts, and the distal humerus was better than the proximal tibia. This suggests that sexual differences in the size of the epiphyseal parts are not simply due to the difference of mechanical stresses that may occur at a particular joint. It is of interest to note that sexual dimorphism has been known to occur in the carrying angle of the elbow and the bicondylar angle of the femur. The relationship of these angular distinctions with the size dimorphism demonstrated above remains to be investigated.

In practice, there are some problems in applying the functions derived in this study to the sexing of the long bones of Japanese skeletal remains of unknown sex. As Iscan et al. (1994) noted the modern Japanese differ in size from that of the recent to modern skeletal series, such as those used in this study. Tagaya (1987) also pointed out population differences of sexual dimorphism among recent Japanese samples. Thus, care must be taken in directly applying the functions of this study. However, the systematic investigation of the present study and the corroborating published evidence summarized above on a wide range of skeletal series provide some insight. It is widely recognized that considerable sexual dimorphism occurs in the carrying angle of the elbow and the bicondylar angle of the femur. The results of the present study strongly suggests that epiphyseal breadths, and in particular those of the elbow and knee joints, should be selected for focus in the determination of sex. In mixed graves where only well-preserved long bones remain, the humerus or tibia might be used in determining sex better than by using the ulna or femur.

\section{Acknowledgements}

The author wishes to express his sincere gratitude to Dr. G. Suwa (The University Museum, The University of Tokyo) and Dr. T. Chiba (Chiba University School of Medicine) for permission to access specimens and for valuable advice. I also thank Dr. G. Suwa and Dr. Y. Dodo (Tohoku University School of Medicine) for their very useful suggestions on this paper.

\section{References}

Asala S.A. (2001) Sex determination from the head of the femur of South African whites and blacks. Forensic Science International, 117: 15-22.

Baba H. (1991) Anthropology. Additional volume 1, II: Osteometry. Yuzankaku, Tokyo (in Japanese).

Black T.K. (1978) A new method for assessing sex of fragmentary skeletal remains: femoral shaft circumference. American Journal of Physical Anthropology, 48: 227-232.

Dibennardo R. and Taylor J.V. (1983) Multiple discriminant function analysis of sex and race in the postcranial skeleton. American Journal of Physical Anthropology, 61: 305-314.

Dittrick J. and Suchey J.M. (1986) Sex determination of prehistoric central California skeletal remains using discriminant analysis of the femur and humerus. American Journal of Physical Anthropology, 70: 3-9.

Dwight T. (1904/05) The size of articular surfaces of the long bones as characteristic of sex: an anthropological study. American Journal of Anatomy, 4: 19-31.

Hanihara K. (1958) Sexual diagnosis of Japanese long bones by means of discriminant function. Journal of the Anthropological Society of Nippon, 66: 187-196.

Holland T.D. (1991) Sex assessment using the proximal tibia. American Journal of Physical Anthropology, 85: 221-227.

Holman D.J. and Bennett K.A. (1991) Determination of sex from arm bone measurements. American Journal of Physical Anthropology, 84: 421-426.

Iscan M.Y. and Miller-Shaivitz P. (1984) Determination of sex from the tibia. American Journal of Physical Anthropology, 64: 53-57.

Iscan M.Y., Yoshino M., and Kato S. (1994) Sex determination from the tibia: standards for contemporary Japan. Journal of Forensic Sciences, 39: 785-792.

Iscan M.Y., Loth S.R., King C.A., Shihai D., and Yoshino M. (1998) Sexual dimorphism in the humerus: a comparative analysis of Chinese, Japanese and Thais. Forensic Science International, 98: 17-29.

Krogman W.M. (1962) The Human Skeleton in Forensic Medicine. Charles C. Thomas, Springfield.

Liu W. (1989) Sex discriminant analysis of long bones of upper limb. Acta Anthropologica Sinica, 8: 231-239.

Liu W., Yang M., and Tai F. (1989) Sex discriminant analysis of long bones of lower limb. Acta Anthropologica Sinica, 8: 147-154.

Mall G., Hubig M., Buttner A., Kuznik J., Penning R., and Graw M. (2001) Sex determination and estimation of stature from the long bones of the arm. Forensic Science International, 117: 23-30.

Nakahashi T. and Nagai M. (1986) Sex assessment of fragmentary skeletal remains. Journal of the Anthropological Society of Nippon, 94: 289-305.

Pons J. (1955) Sexual diagnosis of isolated bones of the skeleton. Human Biology, 27: 12-21.

Purkait R. (2001) Measurements of ulna-a new method for determination of sex. Journal of Forensic Sciences, 46: 924-927.

Safont S., Malgosa A., and Subira M.E. (2000) Sex assessment on the basis of long bone circumference. American Journal of 
Physical Anthropology, 113: 317-328.

Sakaue K. (1997) Bilateral asymmetry of the humerus in Jomon people and modern Japanese. Anthropological Science, 105(4): 231-246.

Tagaya A. (1987) Interpopulation variation of sex differences: an analysis of the extremity long bone measurements of Japa- nese. Journal of the Anthropological Society of Nippon, 95: 45-76.

Van Gerven D.P. (1972) The contribution of size and shape variation to patterns of sexual dimorphism of the human femur. American Journal of Physical Anthropology, 37: 49-60. 